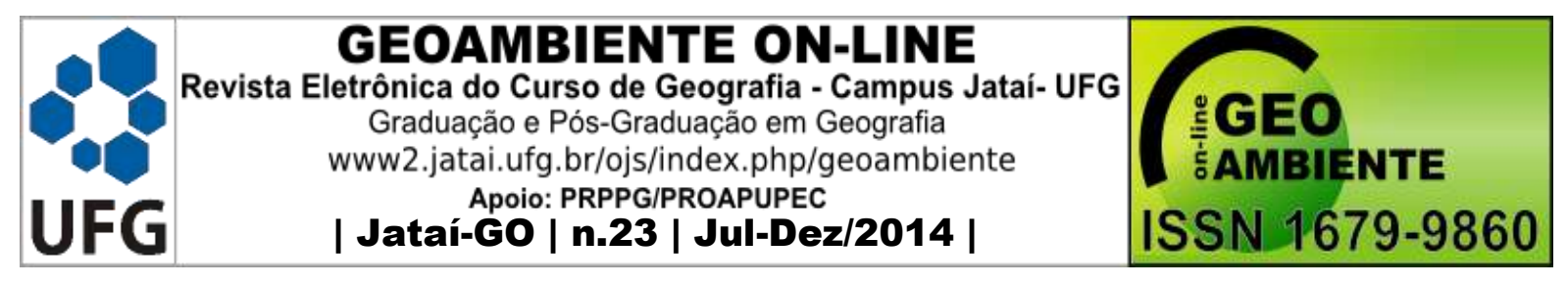

\title{
GAMAESPECTROMETRIA DE UM LIXÃO DESATIVADO
}

\author{
Vitor Rodolfo Becegato ${ }^{1}$, Josiani Cordova ${ }^{2}$, Augusto Schütz Ferreira ${ }^{1}$, Maisa
}

\section{Barrionuevo $^{3}$}

(1 - Universidade do Estado de Santa Catarina - UDESC; Acadêmico do curso de Engenharia Ambiental; Vitortiburon_92@hotmail.com; $\quad$ augustoschutz@hotmail.com; gumaxd@hotmail.com; 2- Universidade do Estado de Santa Catarina - UDESC, Mestranda do curso de Engenharia Florestal; josiani.oliv@gmail.com; 3 - Engenheira Ambiental; maiisab@hotmail.com)

\section{RESUMO}

O presente trabalho foi desenvolvido em um lixão desativado do município de Lages-SC durante o ano de 2014. Foram quantificadas as concentrações dos elementos radioativos (Urânio, Tório e Potássio). O lixão desativado do município de Lages-SC localizado entre as coordenadas $27^{\circ} 46^{\prime} 15,38^{\prime}$ 'S e $50^{\circ} 15^{\prime} 10,92^{\prime}$ 'O em uma área de $48.000 \mathrm{~m}^{2}$ com extensa rede de drenagem, cujo entorno encontram-se áreas de proteção permanente e reflorestamentos com pinus. Efetuou-se a aquisição de dados gamaespectrométricos com o aparelho Pico Envirotec PGIS-2 em cinco células onde se encontram depositados os resíduos sólidos objetivando detectar a presença dos elementos radioativos: $\left({ }^{40} \mathrm{~K} ;{ }^{232} \mathrm{Th} ;{ }^{238} \mathrm{U}\right)$ que apresentaram valores máximos e coeficiente de variação respectivamente: ${ }^{40} \mathrm{~K}\left(7,342 \times 10^{-5}\right.$ ppm; 43,1\%); ${ }^{232} \mathrm{Th}\left(8,43\right.$ ppm; 96,4\%) e ${ }^{238} \mathrm{U}(0,7$ ppm; 93,4\%).

Palavras-chave: Radioatividade, lixão, gamaespectrometria.

\section{ABSTRACT}

\section{GAMMASPECTROMETRY OF A DISABLED LANDFILL}

The present work was developed in the disabled landfill of the municipality of Lages-SC, during the year of 2014. The concentration values of radioactive elements (uranium, thoruim and potassium) have were quantified. The Lages-SC disabled landfill is located between the geographic coordinates $27^{\circ} 46^{\prime} 15,38^{\prime \prime} \mathrm{S}$ and $50^{\circ} 15^{\prime} 10,92^{\prime \prime} \mathrm{W}$ on a $48000 \mathrm{~m}^{2}$ area with an extensive drainage network. On its surroundings there are permanent protection areas and

Artigo recebido para publicação em 08 de Junho de 2014

Artigo aprovado para publicação em 14 de Novembro de 2014 


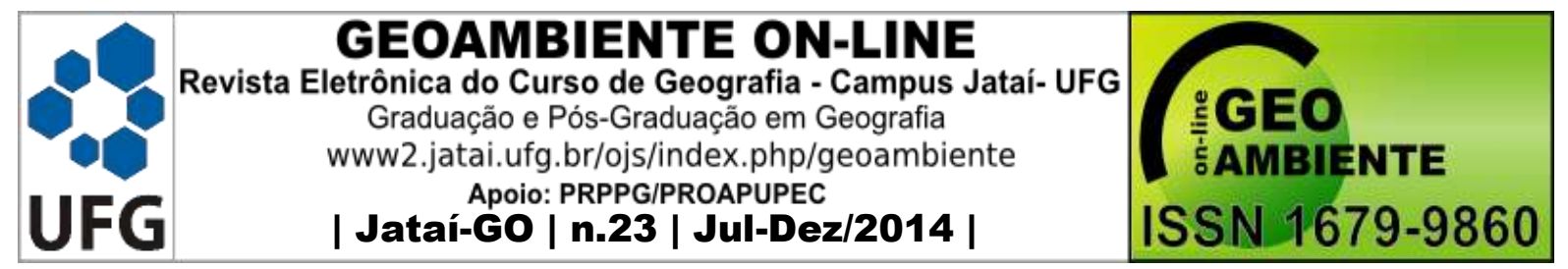

reforesting areas filled with Pinus elliotti. The data aquisition was realized with the Pico Envirotec PGIS-2 gammaspectrometer on five cells where the waste was deposited, with the objective of detecting the presence of the following radionuclides: $\left({ }^{40} \mathrm{~K} ;{ }^{232} \mathrm{Th} ;{ }^{238} \mathrm{U}\right)$, which presented, respectively, values of maximum and variation coefficient: ${ }^{40} \mathrm{~K}\left(7,342 \times 10^{-5} \%\right.$; $43,1 \%) ;{ }^{232} \mathrm{Th}(8,43 \mathrm{ppm} ; 96,4 \%)$ and ${ }^{238} \mathrm{U}(0,7 \mathrm{ppm} ; 93,4 \%)$.

Keywords: Radioactivity, landfill, gammaspectrometry.

\section{RESUMEN}

\section{GAMASPECTROMETRÍA DE UM VERTEDERO DESACTIVADO}

El presente trabajo fue desarollado en un vertedero desactivado en la municipalidad de LagesSC, durante el año de 2014. Los valores de concentración de elementos radioactivos (uranio, torio y potasio) fueron cuantificados. El vertedero desactivado de la municipalidad de LagesSC está ubicado entre las coordenadas geográficas $27^{\circ} 46^{\prime} 15,38^{\prime}$ 'S y $50^{\circ} 15^{\prime} 10,92$ '” O, en un área de $48000 \mathrm{~m}^{2}$ com una larga red de drenaje y repoblaciones forestales con Pinus elliotti. La adquisición de los datos fue realizada con el gamaespectrómetro Pico Envirotec PGIS-2 en cinco células donde estaban depositados los resíduos, con el objetivo de detectar la presencia de los siguientes radionucleidos: $\left({ }^{40} \mathrm{~K} ;{ }^{232} \mathrm{Th} ;{ }^{238} \mathrm{U}\right)$, que presentaron valores máximos y de coeficiente de variación, respectivamente: ${ }^{40} \mathrm{~K}\left(7,342 \times 10^{-5} \% ; 43,1 \%\right) ;{ }^{232} \mathrm{Th}(8,43 \mathrm{ppm}$; $96,4 \%)$ y ${ }^{238} \mathrm{U}(0,7 \mathrm{ppm} ; 93,4 \%)$.

Palabras clave: Radioactividad, vertedero, gamaspectrometría.

\section{INTRODUÇÃO}

O método gamaespectrométrico teve como propósito inicial, conforme Vasconcellos et al. (1994), a sua aplicação em prospecção mineral e mapeamentos geológicos. Entretanto, segundo Dickson et al. (1996), Dickson e Scott (1997), Wilford et al. (1997) e Thiessen et al. (1999) a gamaespectrometria começou a ganhar espaço em estudos ambientais e pedológicos.

A técnica consiste na medição da concentração em rochas e solos dos radioisótopos do potássio $\left({ }^{40} \mathrm{~K}\right)$ e das séries do Urânio $\left({ }^{238} \mathrm{U}\right)$ e do Tório $\left({ }^{232} \mathrm{Th}\right)$, as principais fontes de radiação Becegato (2005).

Existem três tipos de radiação provenientes do interior dos átomos: partículas ou raios alfa, partículas ou raios beta e raios gama. As partículas alfa $(\alpha)$, de acordo com o autor, possuem um baixo poder de penetração em solos e rochas, já que possuem alta probabilidade 


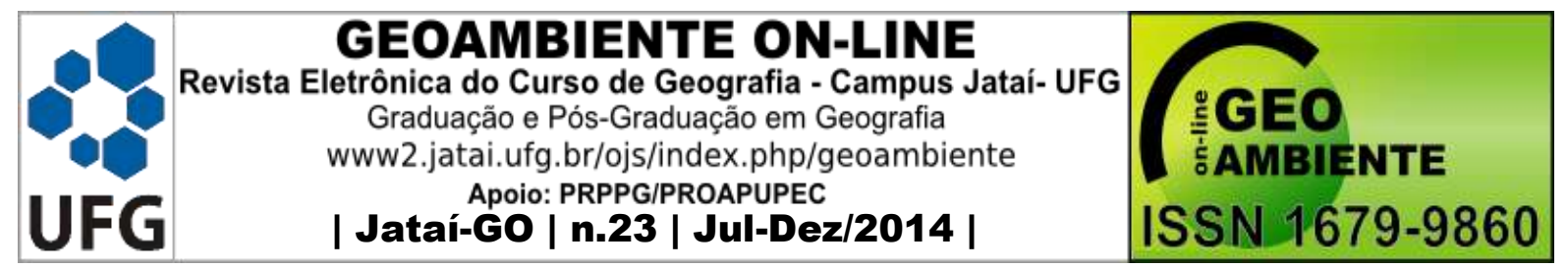

de colisão com outras partículas. As partículas beta $(\beta)$ são elétrons que resultam da transformação de um nêutron em um próton. A absorção completa das partículas $\beta$ se dá em cerca de 1 metro no ar e têm penetração praticamente desprezível nas rochas (BECEGATO, 2005). Os raios gama $(\gamma)$ consistem de radiação eletromagnética de alta energia emitida por um núcleo excitado quando este decai para um estado de menor excitação. Eletricamente neutros e constituídos de radiação eletromagnética (fótons) de frequência superior ao do espectro da luz visível e a dos raios $\mathrm{X}$, os raios gama são emitidos quando os núcleos efetuam transições, por decaimento alfa, de estados excitados para os de energia mais baixa. Sua energia e capacidade de penetração dificultam a manipulação (BECEGATO, 2005).

Segundo Minty (1997), a capacidade de penetração dos raios gama é 100 vezes superior ao dos raios beta, podendo chegar a 30 metros em solos e a centenas de metros no ar. $\mathrm{O}$ autor enfatiza que isto se deve ao fato de que os raios gama não possuem massa nem carga elétrica.

Para efetuar as medições, são utilizados os gamaespectrômetros, equipamentos que separam as radiações gama em duas ou mais componentes de energia. $\mathrm{O}$ detector, normalmente um cristal de iodeto de sódio ativado por tálio $\mathrm{NaI}(\mathrm{Tl})$, absorve a radiação gama e a transforma em pulsos luminosos ou cintilações. Estas cintilações são convertidas em sinais elétricos proporcionais à intensidade da luz, cujas medidas em Volts são separadas em classes, de modo a obter um espectro de energia dos raios gama incidentes (HANSEN, 1975).

A concentração dos elementos é diretamente proporcional à intensidade da radiação gama emitida pelo decaimento radioativo destes isótopos (WILFORD et al., 1997).

Os levantamentos podem ser feitos tanto por via aérea (por meio do uso de gamaespectrômetros acoplados em aeronaves) quanto terrestre, com o uso de equipamentos portáteis.

A radiação gama no solo é inversamente proporcional à densidade do meio que atravessa, sendo que qualquer matéria contida entre o emissor e o sensor pode afetar significativamente a detecção dos raios gama. Isto faz com que as medições radiométricas sejam essencialmente superficiais, tendo um alcance médio de 30 a $40 \mathrm{~cm}$ de profundidade (MINTY, 1988). As principais fontes de interferência em medidas gamaespectrométricas, segundo Ribeiro et al. (2013), são as seguintes:

- Cobertura de solo (35 cm de solo são capazes de atenuar cerca de 95\% da emissão gama); 


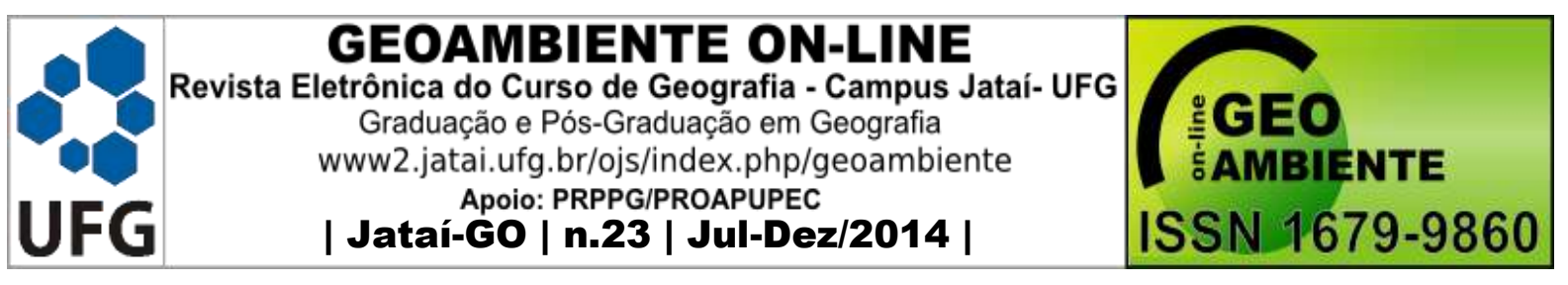

- Vegetação densa (a vegetação é capaz de absorver esses elementos atenuando as medidas de urânio e tório e diminuindo em até $15 \%$ as de potássio);

- Umidade do solo;

- Variações de temperatura atmosférica (que influencia a densidade do ar);

- Umidade relativa e presença de nuvens;

- Fenômeno de inversão térmica, que pode impedir a dissipação do radônio livre na atmosfera gerando falseamento dos dados;

- Grande variação topográfica;

- Distância entre o sensor do espectrômetro e a superfície amostrada e

- Espaçamento entre linhas de aquisição e pontos medidos.

O objetivo desse trabalho foi quantificar a concentração dos elementos radioativos urânio, tório e potássio no lixão desativado do município de Lages-SC (Figura 1) que começou a receber resíduos sólidos urbanos no ano de 1986 e encerrou suas operações em novembro de 2005. Segundo informações da prefeitura de Lages, durante os 18 anos de funcionamento do local foram depositados cerca de $477000 \mathrm{~m}^{3}$ de lixo o que resulta em uma média anual de $26500 \mathrm{~m}^{3}$.

Figura 1 - Recorte da área do Lixão desativado do município de Lages-SC

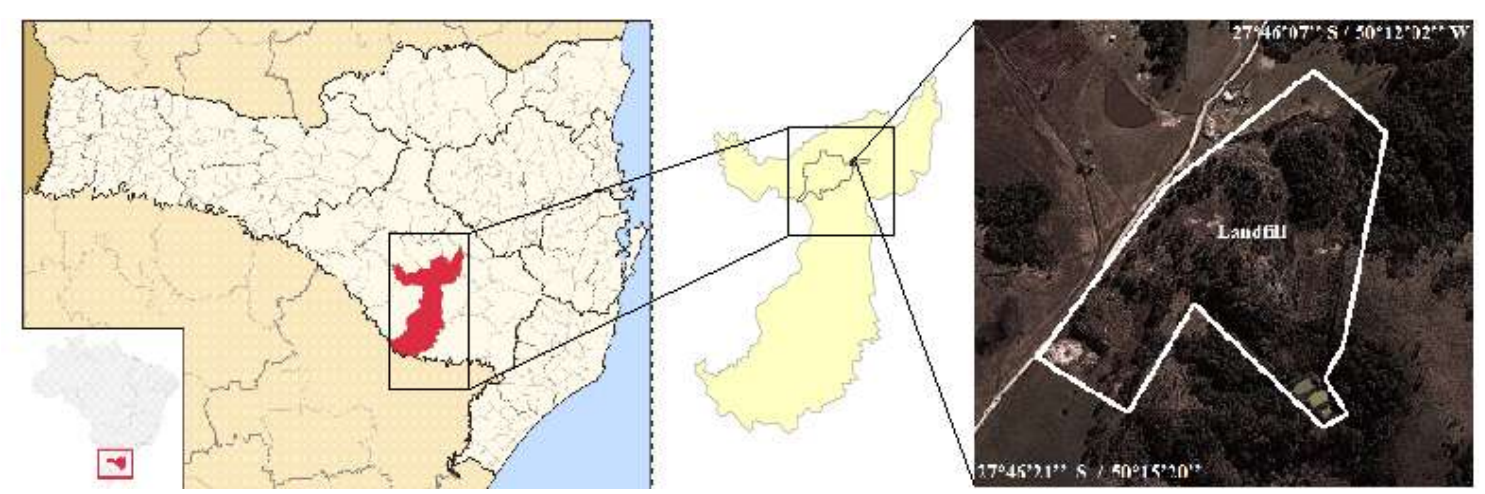

Fonte: Moraes, (2014)

\section{MATERIAL E MÉTODOS}

O equipamento utilizado para medição da radioatividade foi o gamaespectrômetro fabricado pela Pico Envirotec PGIS-2 do Laboratório de Avaliação de Impacto Ambiental do curso de Engenharia Ambiental da UDESC. Além do equipamento para aquisição dos dados, 


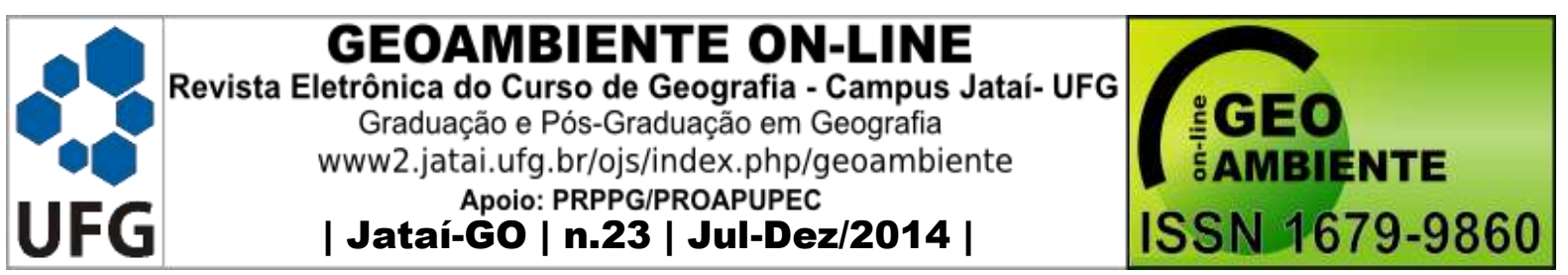

utiliza-se um software para se efetuar a modelagem dos dados e telefone celular que se comunica com o gamaespectrômetro via bluetooth para armazenamento dos dados.

O processo de ligar o equipamento e conectá-lo ao telefone celular via bluetooth foi iniciado (Figura 2). O aparelho foi ligado com sucesso; logo após, o modo bluetooth do telefone foi configurado de modo a não desligar automaticamente e, finalmente, acionado. $\mathrm{O}$ pareamento com o gamaespectrômetro foi realizado com êxito. Testou-se o software PEICore, instalado no telefone; o aplicativo foi iniciado e após alguns segundos de espera, seu menu inicial foi aberto.

Figura 2. Tela inicial do aplicativo PEICore.

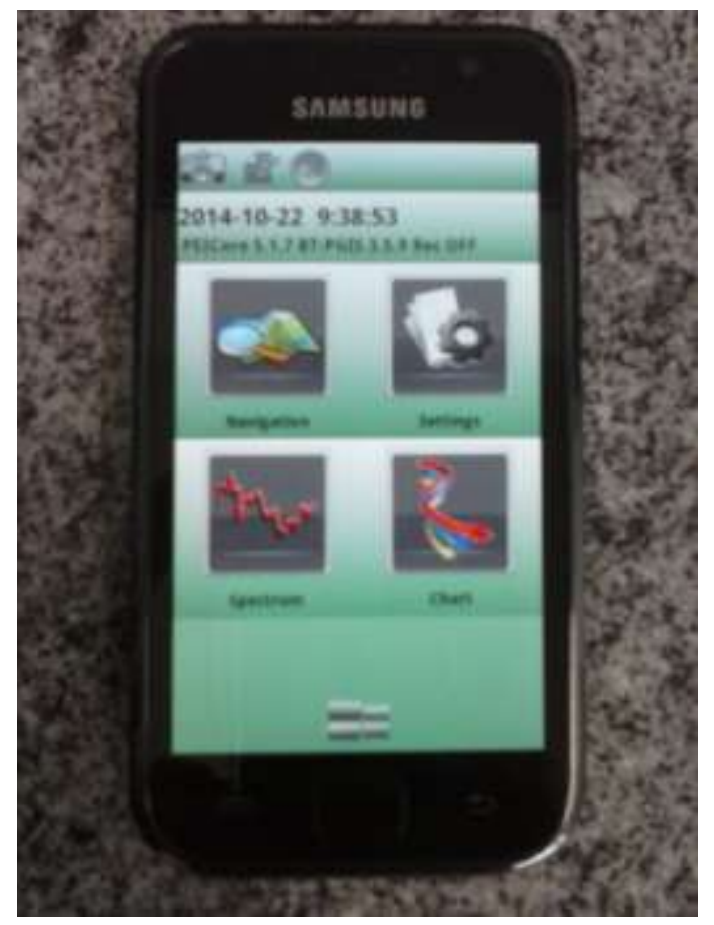

Antes da aquisição dos dados, um mapa georreferenciado do lixão com base em uma imagem do Google Earth foi elaborado e transferido para o telefone, uma vez que o aplicativo PEICore guia o usuário com base neste mapa. Após o recorte da área desejada, utilizou-se sete pontos com marcadores de coordenadas foram inseridos na imagem: quatro nos vértices, um no centro e outros dois paralelamente, para que o software PEIConvert pudesse posteriormente georreferenciar a imagem corretamente. As coordenadas geográficas de cada marcador foram salvas em um arquivo de texto e a imagem foi salva no formato bitmap (bmp) de 256 cores para que o processo de elaboração do mapa pudesse prosseguir. 


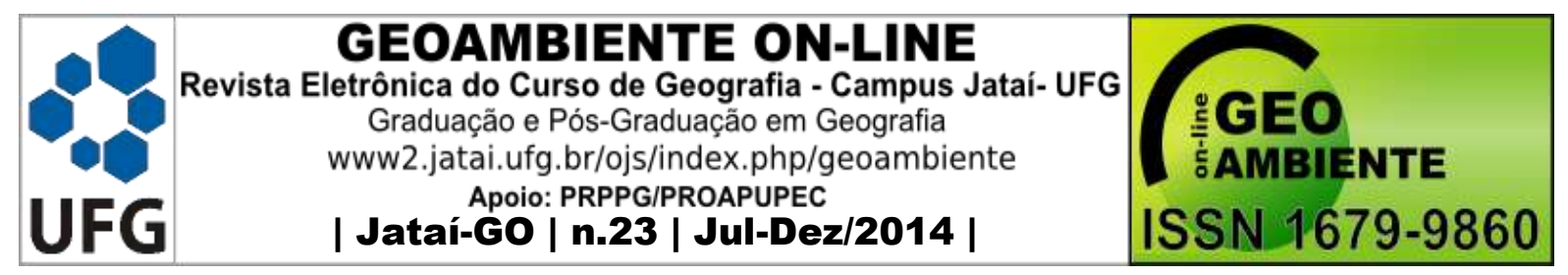

Para a continuação do processo, o software PEIConvert foi inicializado. A imagem gerada foi aberta e a opção de georreferenciamento na Projeção Universal Transversa de Mercator foi selecionada (Figura 3).

Figura 3. Escolha da Projeção para Georeferenciamento da imagem

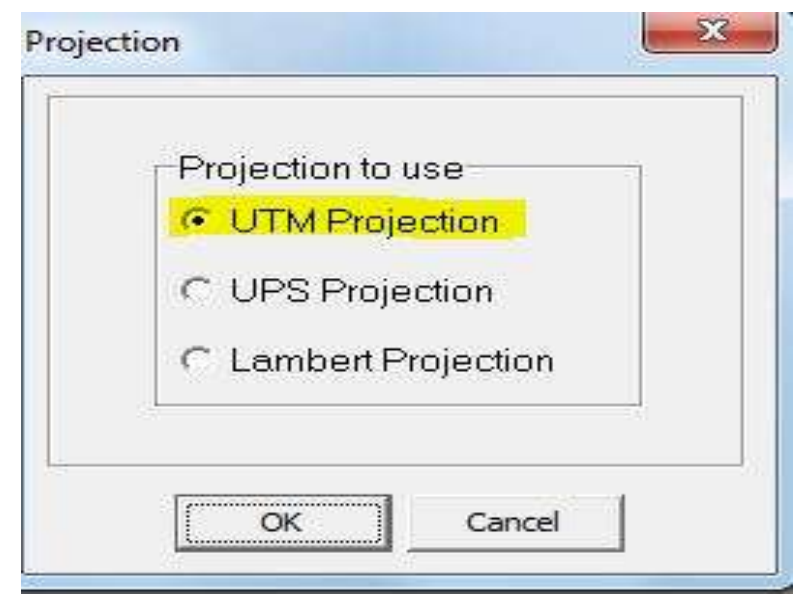

$\mathrm{Na}$ sequência foi efetuado a configuração com dados relativos ao tipo de elipsoide utilizado, valores de latitude e longitude em graus da região, e à Zona UTM correspondente no menu View e depois em Show Table (Figura 4).

Figura 4. Dados de localização para georeferenciamento de imagens.

\begin{tabular}{|c|c|c|c|c|c|c|}
\hline 1] Table Form & & & & & a & 回 $\mid x^{2}$ \\
\hline Ellipsoid: WGS-84 & 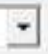 & Approx. Long & 49 & W & Zone: & 22 \\
\hline & & Approx. Lat & 27 & $S$ & Central Meridian: & \\
\hline
\end{tabular}

Após o preenchimento destes dados, deu-se um clique duplo no centro de cada marcador contido na imagem, em ordem numérica. Com isso, as coordenadas de cada um, referentes ao plano cartesiano do programa, foram automaticamente inseridas em uma tabela fornecida pelo próprio software. As coordenadas geográficas salvas no arquivo de texto previamente mencionado foram copiadas e adicionadas à mesma tabela (Figura 5).

Selecionou-se a opção Recalculate Coordinates e a imagem teve suas coordenadas geográficas inseridas no plano cartesiano do programa e a imagem foi georreferenciada. Salvou-se a imagem e esta foi transferida para o telefone celular. 


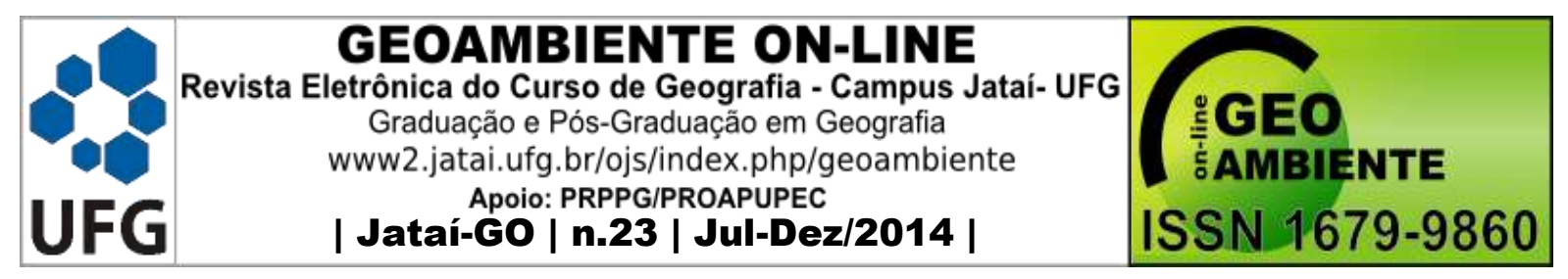

Figura 5. Valores de coordenadas geográficas dos marcadores de imagem.

\begin{tabular}{|c|c|c|c|c|c|c|c|c|}
\hline 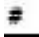 & $x$ & $Y$ & Longitude & Latitude & Easting & Horthing & $\mathrm{N} / \mathrm{S}$ & $E / W$ \\
\hline 1 & 680 & 67 & 50,30135779 & 27,78673581 & 568828 & 6926226 & $\mathbf{S}$ & $w$ \\
\hline 2 & 825 & 582 & 50,29942115 & 27,79274714 & 569015 & 6925559 & $\mathbf{S}$ & $w$ \\
\hline 3 & 301 & 670 & 50,30624665 & 27,79369333 & 568342 & 6925458 & $\mathbf{S}$ & $w$ \\
\hline 4 & 203 & 139 & 50,30749279 & 27,78766941 & 568223 & 6926126 & $\mathbf{S}$ & $w$ \\
\hline 5 & 506 & 355 & 50,30362001 & 27,7901234 & 568603 & 6925852 & $\mathbf{S}$ & $w$ \\
\hline
\end{tabular}

Os locais de aquisição dos dados foram previamente definidos, sendo que a metodologia utilizada foi pelo método de caminhos retilíneos e perpendiculares uns aos outros (Figura 6), de forma que fosse criada uma malha de pontos amostrados. O intervalo de aquisição de dados foi ajustado para realizar medições a cada cinco segundos para evitar um número excessivo de pontos e valores.

Figura 6. Aquisição de dados com o gamaespectrômetro Pico Environtec PGIS-2 e telefone celular.

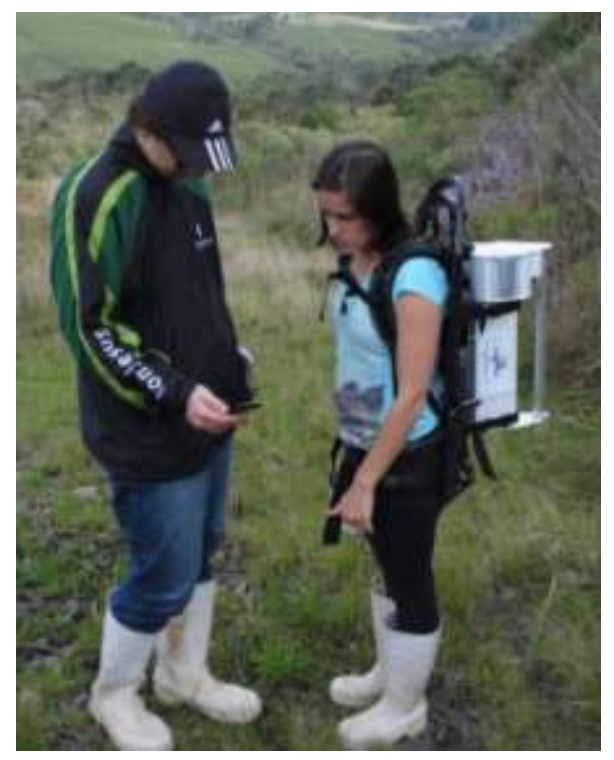

A medição foi dividida em duas partes para que a sobreposição de dados não fosse tão exagerada, já que estes seriam coletados em diferentes células do lixão.

\section{RESULTADOS E DISCUSSÃO}




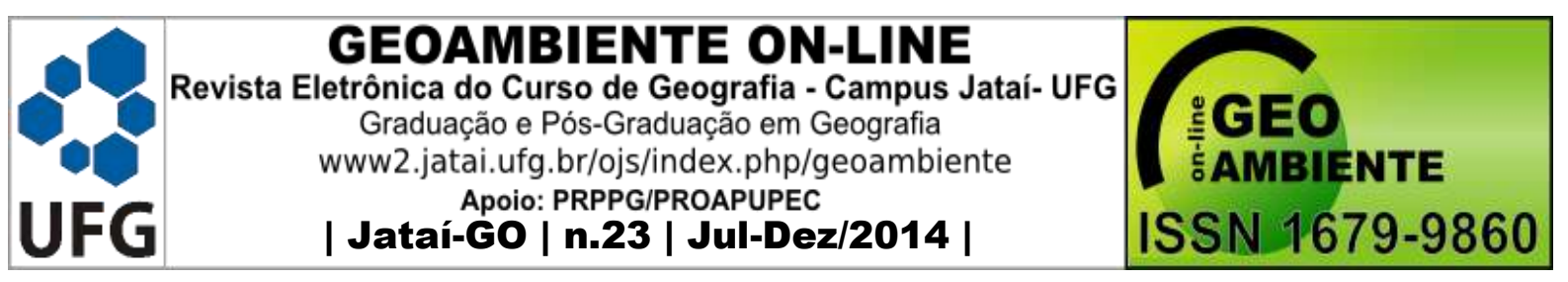

Os arquivos com os dados gravados pelo equipamento foram descarregados para um computador por meio de um cabo USB. Após a transferência, o software PEIView foi inicializado para a leitura. O programa inicialmente mostrou na tela do computador (Figura 7) os resultados dispostos em seis gráficos distintos; no eixo vertical eram representados os valores obtidos, e no horizontal o número da gravação de dados.

Figura 7. Interface do programa PEIView após o carregamento de um arquivo de dados.

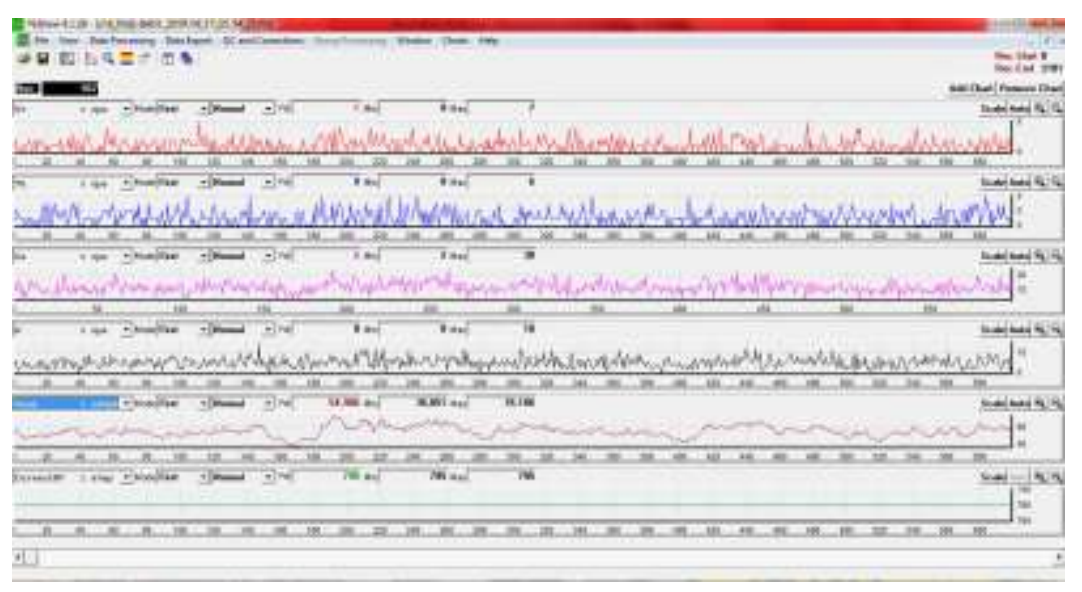

Para simplificar a análise dos dados decidiu-se extrair os valores para uma planilha do Microsoft Excel. Clicou-se duas vezes sobre um dos gráficos apresentados e os dados passaram a ser dispostos em forma de tabela (Figura 8).

Figura 8. Dados exibidos em formato de tabela pelo programa PEIView.

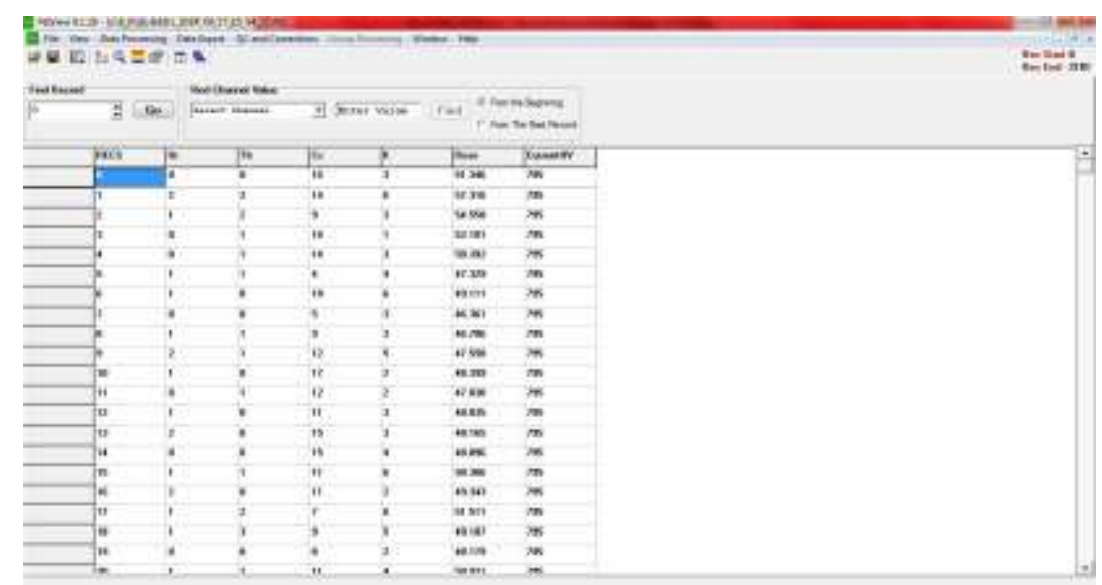




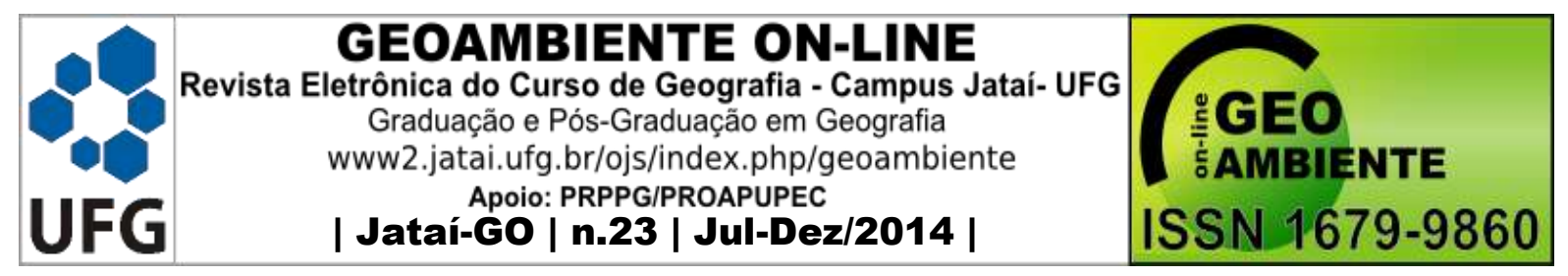

O software não permite que a tabela por ele fornecida seja copiada integralmente para outro programa; apenas um valor por vez. Entretanto, ainda foi possível transferir os valores de uma maneira mais rápida; criando um arquivo no formato .txt e a partir desse arquivo, copiar os valores ao Microsoft Excel. Isto foi feito ao, primeiramente, clicar na opção Data Processing na barra superior e selecionando a opção ASCII Format (Figura 9). Feito isso, o menu de configurações para exportação expresso pela figura a seguir apareceu na tela.

Figura 9. Quadro de seleção de configurações para exportação de arquivos.

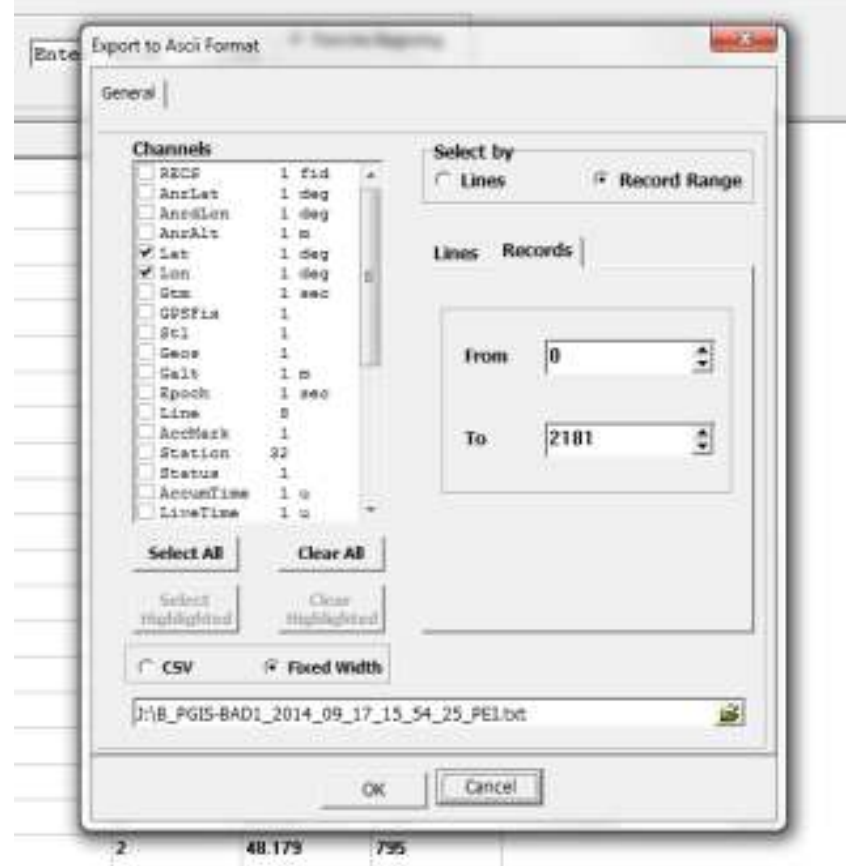

Os parâmetros desejados já estavam selecionados no quadro Channels. Também foram selecionadas as opções Fixed Width (que deixa as colunas de dados uniformemente espaçadas) e Records (que seleciona os dados por gravação). Finalmente, os arquivos foram salvos; podendo ter seu conteúdo copiado, transferido e editado (Figura 10).

O conteúdo de ambos os arquivos foi transferido para o Microsoft Excel, resultando em uma planilha digital. Os valores de urânio, tório e potássio expressos em contagens por segundo, (CPS) foram convertidos para a unidade de partes por milhão (ppm); enquanto que os valores de potássio foram convertidos de CPS para porcentagem. Estas transformações foram efetuadas utilizando os fatores de conversão propostos por Ferreira et al. (2005). Os valores de dose foram convertidos de $\mathrm{nSv} / \mathrm{h}$ para $\mathrm{mSv} / \mathrm{ano}$. 


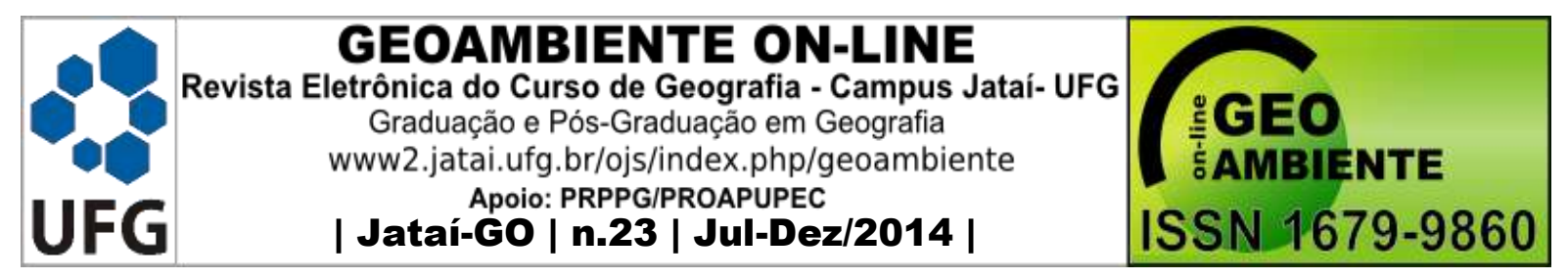

Após as conversões os valores obtidos para cada elemento foram comparados com os sugeridos por Dickson e Scott (1997), Minty (1997), IAEA (2003) e Bonotto (2004); enquanto que os de dose foram comparados com o recomendado pela USEPA (Agência de Proteção Ambiental dos Estados Unidos da América). Posteriormente, foram gerados mapas temáticos de superfície para cada parâmetro com o auxílio do Golden Software Surfer 8.

Figura 10. Arquivo em formato txt para transferência.

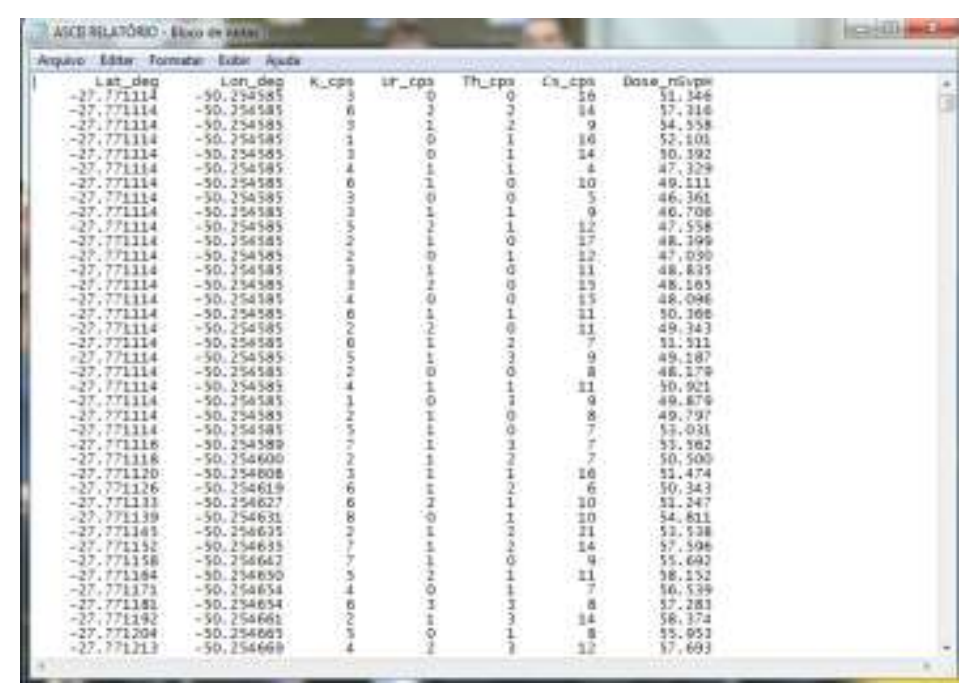

A Tabela 1 mostra os valores obtidos das medições e os compara com os respectivos valores de referência. Nota-se que os valores de potássio estão muito abaixo da faixa indicada pela literatura, sendo que todos os pontos amostrados apresentaram concentrações abaixo de $0,001 \%$. Somente um ponto apresentou um valor de concentração de tório próximo ao mínimo normalmente encontrado, o que levou a concentração média a estar distante do proposto pelos autores. $\mathrm{O}$ urânio teve uma concentração média de $0,12 \mathrm{ppm}$, abaixo dos 2 a 3 ppm comumente encontrados na crosta terrestre, segundo a literatura. As doses de exposição à radiação ionizante permaneceram abaixo do limite máximo (1 mSv/ano) de segurança estabelecido pela USEPA. 


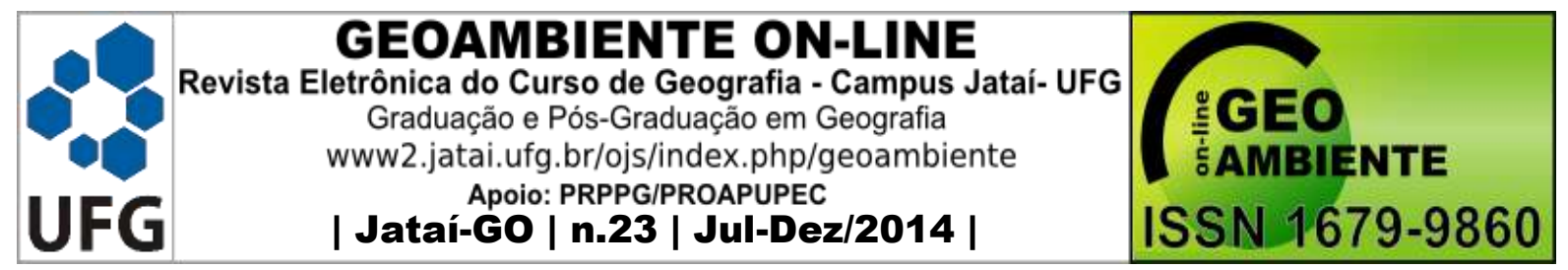

Tabela 1 - Níveis de parâmetros radioativos referentes ao lixão desativado de Lages-SC, comparados com os dados de Dickson e Scott (1997), Minty (1997), IAEA (2003), Bonotto (2004) e pela USEPA.

\begin{tabular}{|c|c|c|c|c|}
\hline Valores & $\begin{array}{c}\text { Potássio } \\
(\%)\end{array}$ & $\begin{array}{l}\text { Tório } \\
\text { (ppm) }\end{array}$ & $\begin{array}{l}\text { Urânio } \\
\text { (ppm) }\end{array}$ & $\begin{array}{c}\text { Dose anual } \\
\text { de } \\
\text { exposição } \\
(\mathrm{mSv})\end{array}$ \\
\hline Mínimo obtido & 0 & 0 & 0 & 0,32 \\
\hline Máximo obtido & $7,342 \times 10^{-5}$ & 8,43 & 0,70 & 0,79 \\
\hline Mínimo usual (literatura) & 2,0 & 8,0 & 2,0 & - \\
\hline Máximo usual (literatura) & 2,50 & 12,00 & 3,00 & - \\
\hline Média & $\begin{array}{c}2,444 \times 10^{-} \\
{ }^{\circ} \%\end{array}$ & 0,64 & 0,12 & 0,55 \\
\hline Mediana & $2,318 \times 10^{-5}$ & 0,56 & 0,1 & 0,55 \\
\hline Moda & $2,705 \times 10^{-5}$ & 0,56 & 0,1 & 0,53 \\
\hline Coeficiente de Variação (\%) & 43,1 & 96,4 & 93,4 & 13,0 \\
\hline Desvio Padrão & $1,05 \times 10^{-5}$ & 0,62 & 0,11 & 0,07 \\
\hline Dose de exposição máxima (USEPA) & - & - & - & 1,0 \\
\hline
\end{tabular}

Os mapas temáticos (Figuras 11 a 14) mostram a distribuição espacial das concentrações dos elementos e dos valores de dose de exposição anual na área do lixão desativado: 


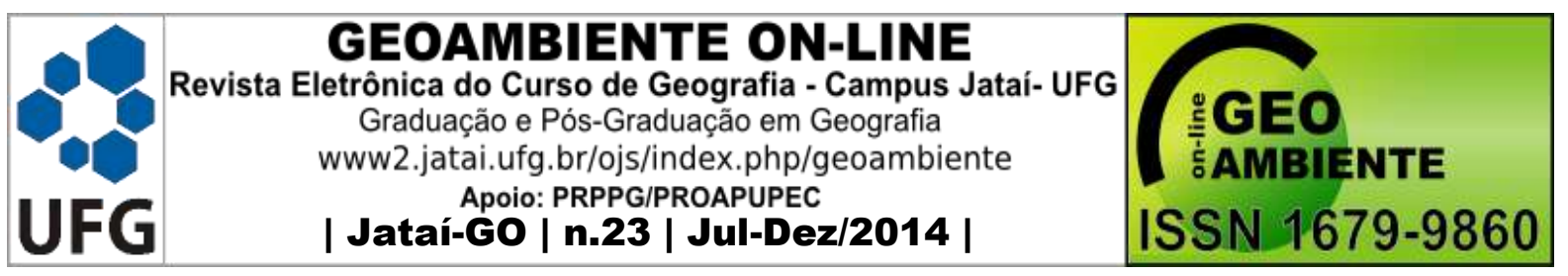

Figura 11. Mapa temático de superfície para valores de potássio.

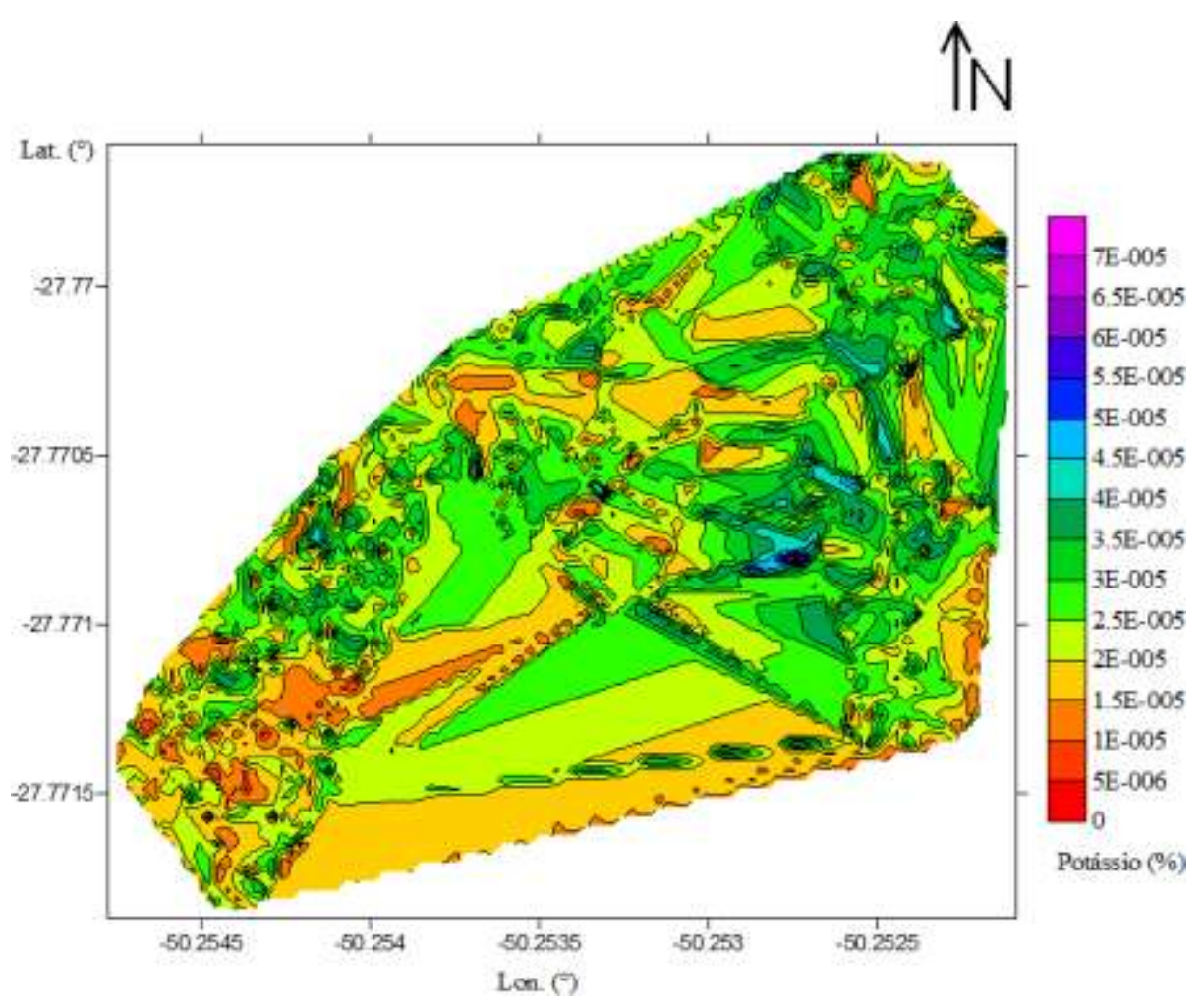

Figura 12. Mapa temático de superfície das concentrações de tório.

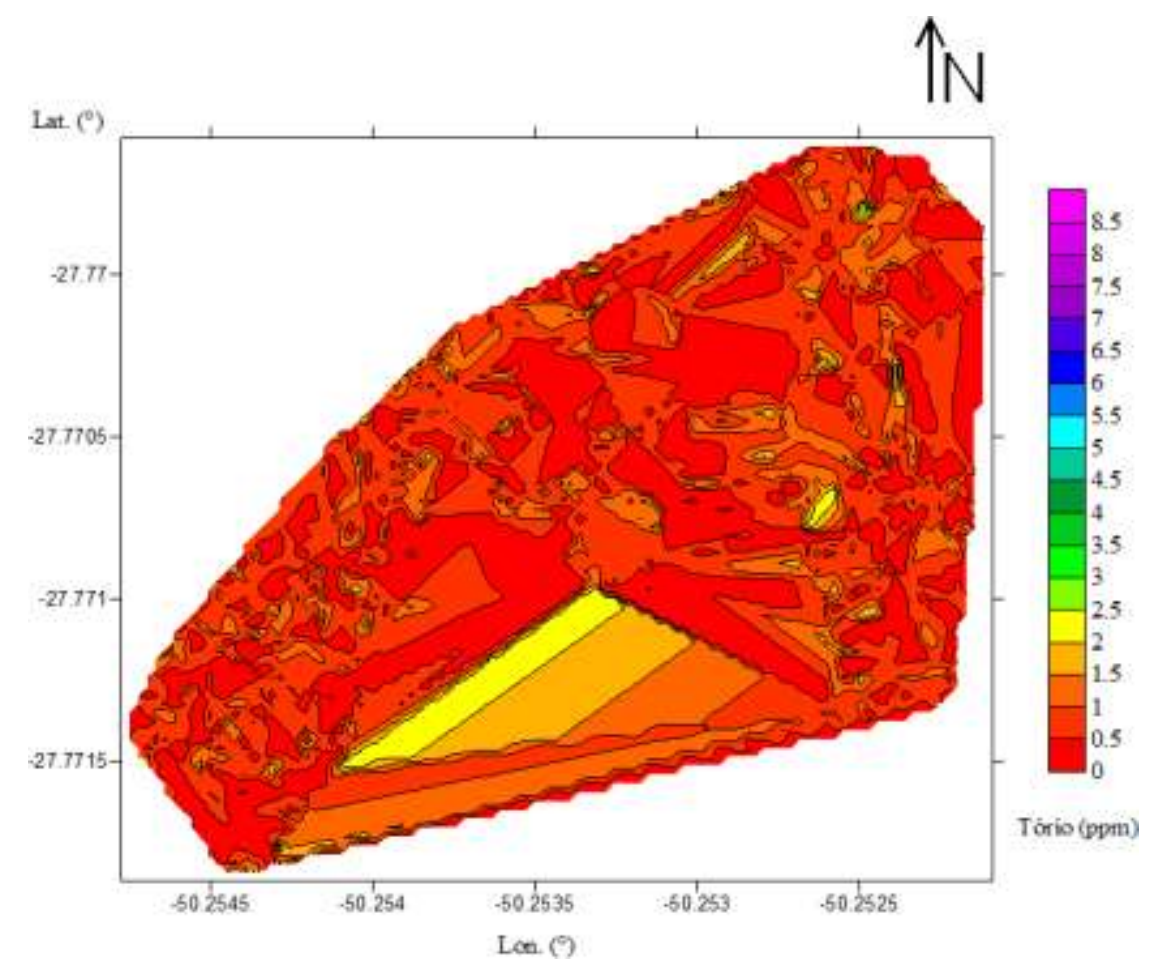




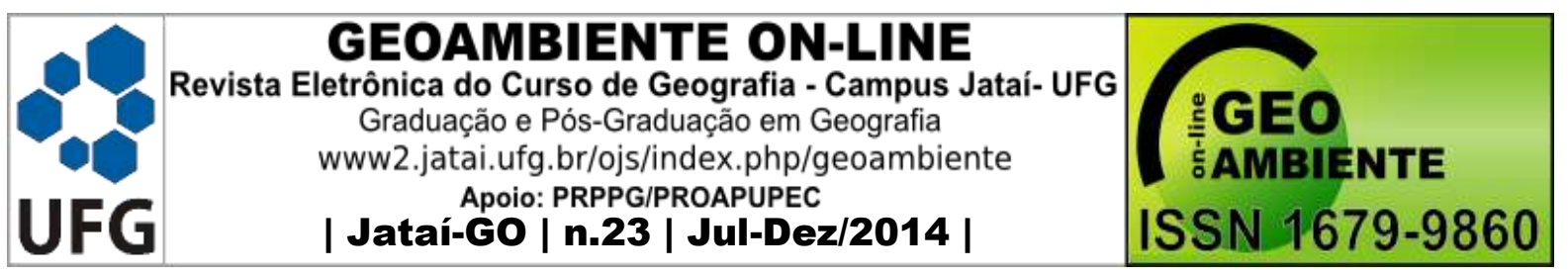

Figura 13. Mapa temático de superfície das concentrações de urânio.

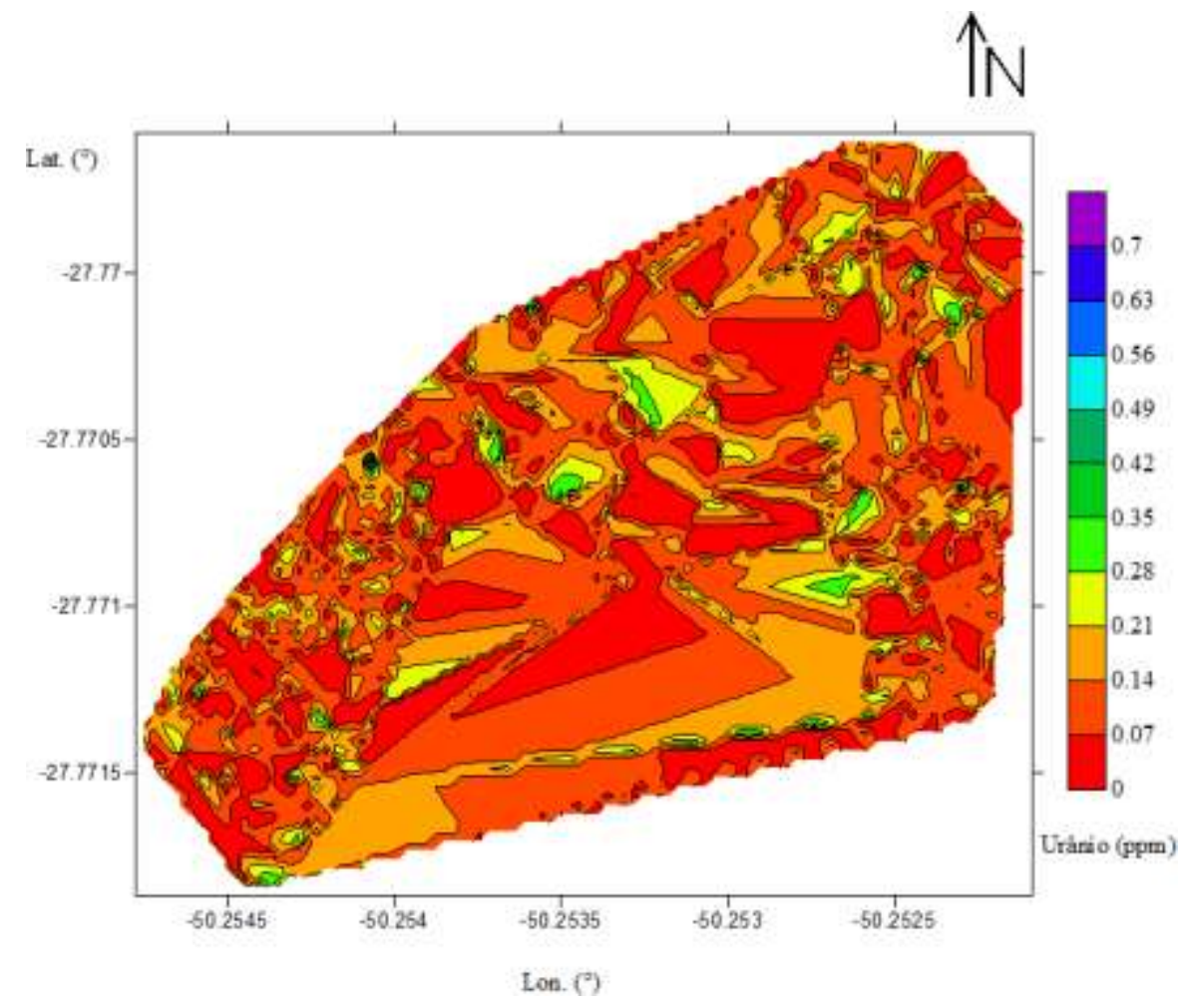

Figura 14. Mapa temático de superfície para os valores de dose anual de exposição à radiação ionizante.

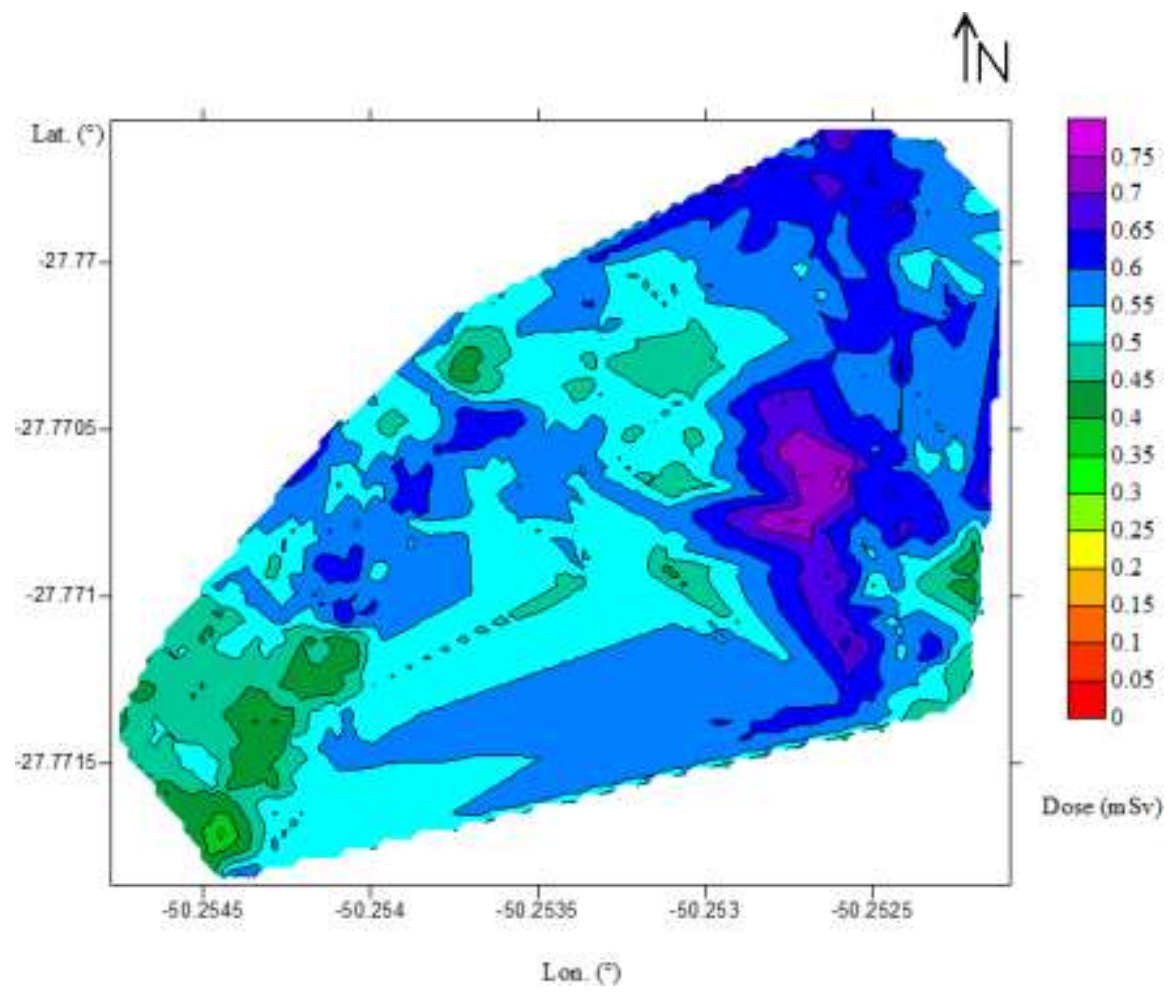




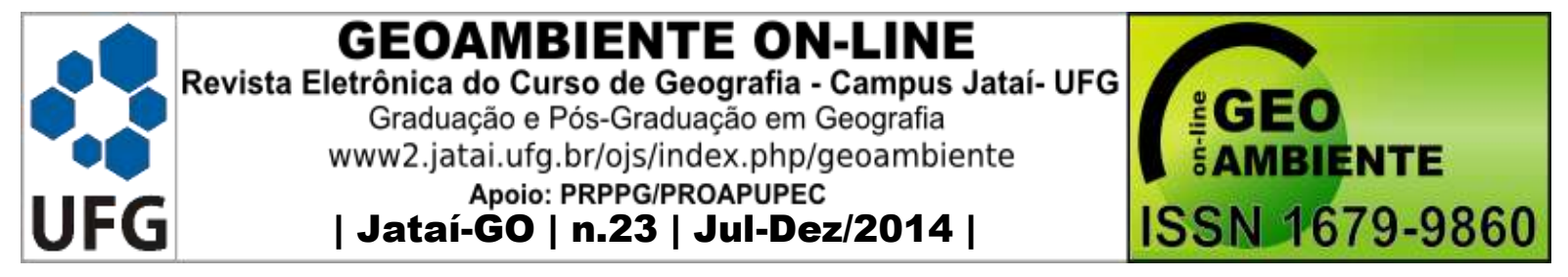

Dickson e Scott (1997), enfatizaram que para um tipo de rocha, pode haver ampla variação das concentrações dos radioelementos. Os referidos autores analisaram teores de elementos radioativos em vários tipos rochas da Austrália, mostrando que devido a grande dispersão dos teores em cada classe de rocha, não é possível estabelecer uma classificação petrográfica com base nas concentrações de radionuclídeos.

De acordo com Wilford et al., (1997), durante o intemperismo químico e físico, os radioelementos são liberados da rocha, redistribuídos e incorporados ao regolito/solo. Em muitos casos, as características dos elementos radioativos de regolitos, podem em muito diferir da origem, devido à reorganização textural e geoquímica que ocorre no perfil intemperizado.

Dowdall e O'Dea (2002) estudando a radioatividade em perfis de solos orgânicos na Irlanda, observaram que há um acréscimo de U nos perfis onde a oxidação da matéria orgânica é significativamente reduzida, o que acontece a partir de aproximadamente $15-20 \mathrm{~cm}$ de profundidade, cuja ausência de oxigênio origina um ambiente predominantemente redutor, desacelerando a decomposição da matéria orgânica pelos microorganismos do solo, e, consequentemente aumentando a capacidade de troca cationica de tais solos, o que culminaria com o aumento da retenção do U.

\section{CONCLUSÃO}

A maior concentração dos elementos radioativos é para o Urânio.

As doses de radioatividade não oferecem riscos ao meio ambiente. No entanto deve-se continuar monitoramento o incremento dos elementos radioativos nos solos e no lixão.

A conexão entre o gamaespectrômetro e o telefone celular agiliza a aquisição dos dados sendo possível cobrir grandes áreas em levantamentos regionais.

A distribuição espacial dos dados georreferenciados no meio ambiente, mostra de forma clara onde ocorrem as maiores concentrações dos elementos radioativos.

\section{REFERÊNCIAS BIBLIOGRÁFICAS}




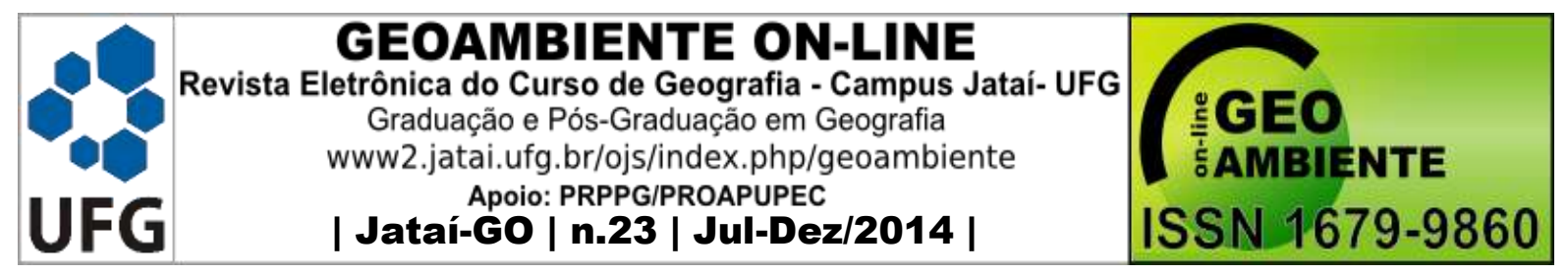

BECEGATO, V.A. Aplicação de técnicas geofísicas e geoquímicas em duas glebas agrícolas do noroeste do Paraná e suas relações com fertilizantes fosfatados. Curitiba, 2005. Tese (Doutorado em Geologia) - Programa de Pós-graduação em Geologia, Universidade Federal do Paraná, 2005.

BONOTTO, D.M. Radioatividade nas águas: da Inglaterra ao Guarani. São Paulo: Editora UNESP, 252 p., 2004.

DICKSON B.L.; SCOTT K.M. Interpretation of aerial gamma-ray surveys - adding the geochemical factors. AGSO Journal of Australian Geology \& Geophysics, v. 17, 187-200p., 1997.

DICKSON, B.L., FRASER, S.J.; KINSEY-HENDERSON A. Interpreting aerial gamma-ray surveys utilising geomorphological and weathering models. Elsevier, Journal of Geochemical Exploration, v. 57, p. 75-88, 1996.

DOWDALL, M.; O’DEA, J. ${ }^{226} \mathrm{Ra}^{238} \mathrm{U}$ disequilibrium in an upland organic soil exhibiting elevated natural radioactivity. Journal of Environmental Radioactivity, v. 59 p. 91-104., 2002.

FERREIRA, F.J.F. et al. Contrastes gamaespectrométricos (K, eTh, eU) dos complexos graníticos Cunhaporanga e Três Córregos-PR: análise dos dados do BARMP (Brazil Airborne Radiometric Mapping Project). In: CONGRESSO BRASILEIRO DE GEOQUÍMICA E SIMPÓSIO DE GEOQUÍMICA DOS PAÍSES DO MERCOSUL, 10., 2005, Porto de Galinhas. Resumos... São Paulo: Sociedade Brasileira de Geoquímica - SBGq, 2005. v. 1.

GOLDEN SOFTWARE, Inc. Surfer. Version 8.00. 2002.

HANSEN, D. A. Geological applications. Manual for Portable Gamma-ray Spectrometers. Toronto, Exploranium G.S. Limited, 87 p., 1975.

INTERNATIONAL ATOMIC ENERGY AGENCY (IAEA). Guidelines for radioelement mapping using gamma ray spectrometry data. Vienna: IAEATECDOC-1363, 173 p., 2003.

MINTY, B.R.S. A review of airborne gamma-ray spectrometric data processing techniques. Australian Government Publishing Service, 48 p., 1988.

MINTY, B.R.S. Fundamentals of airbone gamma-ray spectrometry. AGSO Journal of Australian Geology \& Geophysics, v. 17, n.2, p. 39-50., 1997. 


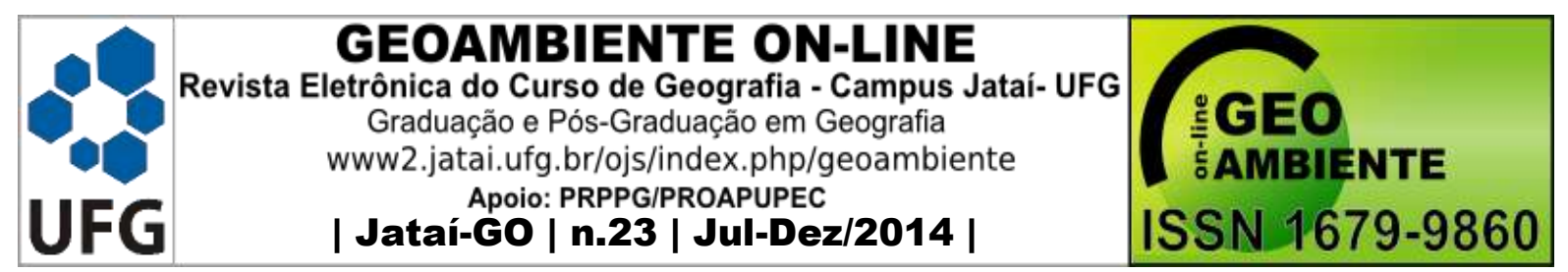

MORAES, C.L. Caracterização do passivo ambiental lixão desativado do município de Lages-SC. Tese de mestrado. Pós-graduação em Engenharia Florestal - UDESC. 2014.

RIBEIRO V.B.; LOURO V.H.A.; MANTOVANI M.S.M. Geophysical study of the Sertãozinho, Rio Aguapeí and Nova anomalies (SW of Mato Grosso, Brazil). In: CONGRESSO INTERNACIONAL DA SOCIEDADE BRASILEIRA DE GEOFÍSICA, 13., 2013. Resumos eletrônicos... Rio de Janeiro: SBGf, 2013. Disponível em: < http://sys2.sbgf.org.br/congresso/abstracts/trabalhos/sbgf_4132.pdf>. Acesso em 31 out. 2014.

THIESSEN, K.M.; THORNE, M.C.; MAUL, P.R.; PRÖHL, G.; WHEATER, H.S. Modelling radionuclide distribution and transport in the environment. Elsevier, Environmental Pollution, v. 100, p. 151-177, 1999.

WILFORD, J. R.; BIERWIRTH, P. N.; CRAIG, M. A. Application of gamma-ray spectrometry in soil/regolith mapping and geomorphology. AGSO Journal of Australian Geology \& Geophysics, v. 17, 201-216 p., 1997. 